\begin{tabular}{|c|c|c|}
\hline \multirow{3}{*}{$\begin{array}{r}\text { Case Reports in } \\
\text { Gastroenterology }\end{array}$} & \multirow{2}{*}{\multicolumn{2}{|c|}{ Case Rep Gastroenterol 2014;8:72-76 }} \\
\hline & & \\
\hline & $\begin{array}{l}\text { DOI: } 10.1159 / 000360844 \\
\text { Published online: March 13, } 2014\end{array}$ & $\begin{array}{l}\text { ○ } 2014 \text { S. Karger AG, Basel } \\
\text { 1662-0631/14/0081-0072 } \$ 39.50 / 0 \\
\text { www.karger.com/crg }\end{array}$ \\
\hline & \multicolumn{2}{|c|}{$\begin{array}{l}\text { This is an Open Access article licensed under the terms of the Creative Commons } \\
\text { Attribution-NonCommercial } 3.0 \text { Unported license (CC BY-NC) (www.karger.com/OA } \\
\text { license), applicable to the online version of the article only. Distribution permitted for non } \\
\text { commercial purposes only. }\end{array}$} \\
\hline
\end{tabular}

\title{
Cephalic Duodenopancreatectomy for Hyperalgic Duodenal Crohn's Disease Fistulized in the Pancreatic Gland
}

\author{
Sabra Guellouz ${ }^{\mathrm{a}} \quad$ Benjamin Pariente $^{\mathrm{a}}$ Claire Benet $^{\mathrm{b}}$ \\ Clotilde Baudry $^{a} \quad$ Nelson Lourenco ${ }^{a} \quad$ Aurore Kraemer $^{c}$ \\ Matthieu Allez ${ }^{a}$ Jean-Marc Gornet ${ }^{a}$ \\ ${ }^{\mathrm{a}}$ Hepato-Gastroenterology Department, ${ }^{\mathrm{b}}$ Pathology Department and \\ 'Surgery Department, Saint-Louis Hospital, Université Paris VII, Paris, France
}

\section{Key Words}

Crohn's disease · Fistula · Cephalic duodenopancreatectomy

\begin{abstract}
Upper gastrointestinal (GI) tract involvement in adult Crohn's disease (CD) is rare and severe complications unusual. Stenosis has been reported, but gastroduodenal fistulae are seldom detected during surgery and most of the fistulae are cologastric or ileogastric. In complicated gastroduodenal $C D$, medical treatments are often effective and surgery is only considered in exceptional cases. We here report the unusual case of a 23 -year-old patient with upper GI CD presenting a hyperalgic giant ulcer of the bulb fistulized in the pancreatic gland. The failure of steroids and two lines of combined treatment led us to a salvage surgical option. Abdominal exploration showed a plate stomach with an inflammatory bulboduodenal block. Cephalic duodenopancreatectomy and cholecystectomy were performed; histological analysis reported large fissuring pylorus ulceration with micro abscesses reaching the pancreas and the presence of non-caseating granulomas. Six months after the surgery, the patient had stopped antalgic treatment and did not have residual abdominal pain. He had gained $11 \mathrm{~kg}$ in weight and had no diarrhea with pancreatic enzymes. To our knowledge, we report the first case of an upper GI and fistulizing CD patient heavily treated with steroids and combined immunosuppressant agents requiring salvage cephalic duodenopancreatectomy.
\end{abstract}


Guellouz et al.: Cephalic Duodenopancreatectomy for Hyperalgic Duodenal Crohn's Disease Fistulized in the Pancreatic Gland

\section{Introduction}

Inflammatory bowel disease is a chronic inflammatory disorder that comprises Crohn's disease (CD) and ulcerative colitis. Both CD and ulcerative colitis are chronic and progressive diseases, but $C D$ is specially considered as a destructive disease, leading to fibrostenotic stricture or penetrating lesions of the bowel resulting in structural bowel damage [1]. Surgical intestinal resection is frequently required to treat strictures, fistulae or abscesses, and it should be considered as the ultimate manifestation of bowel damage [1]. Up to $80 \%$ of CD patients require abdominal surgery for intestinal or colonic CD complications. Nevertheless, upper gastrointestinal (GI) tract involvement in adult CD is rare $(<15 \%$ of patients) and severe complications unusual; for these reasons, surgery for upper GI CD is only considered in exceptional cases, in whom gastrojejunostomy is the most common procedure. We here report the unusual case of a 23-year-old patient with upper GI CD presenting a hyperalgic giant ulcer of the bulb fistulized in the pancreatic gland and treated by cephalic duodenopancreatectomy, regarding the failure of medical treatments.

\section{Case Report}

We report herein the case of a 23-year-old man with a past history of gastric pain in 1999 in relation with an ulcer of the bulb successfully treated by proton pomp inhibitors. Between 1999 and 2008, the patient had no symptoms. In October 2008, the abdominal pain reappeared with anorexia and weight loss (from 67 to $54 \mathrm{~kg}$ ). Upper digestive endoscopy showed a giant ulcer covering the whole surface of the bulb (fig. 1). Histological analysis reported antral gastritis, presence of Helicobacter pylori and non-caseating granulomas composed of epithelioid cells and multinucleated giant cells. Ziehl staining and quantiferon test were negative. Chest X-ray did not show any abnormality. C-reactive protein was $10 \mathrm{mg} / \mathrm{l}$, hemoglobin level $12.2 \mathrm{~g} / \mathrm{dl}$ with a mean corpuscular volume at $81 \mathrm{fl}$, and the gastrin blood rate was normal.

The diagnosis of duodenal CD was strongly suspected. However, we first decided to treat H. pylori infection with a 7-day regimen of proton pomp inhibitor b.i.d., amoxicillin $1 \mathrm{~g}$ b.i.d. and a $500 \mathrm{mg}$ metronidazole b.i.d., without evidence of clinical improvement. A second upper digestive endoscopy confirmed the persistence of a large ulcer with suspicion of a plugged perforation and a stenosis of the bulboduodenal junction. Non-caseating granulomas without $H$. pylori were still found on biopsies.

To assess the extent of CD, ileocolonoscopy with multiple biopsy sampling, abdominal computed tomography and capsule endoscopy were performed. On ileocolonoscopy, the ileum and colon were macroscopically and microscopically healthy. The abdominal computed tomography scan only reported thickening of the pylorus wall and bulb. The capsule endoscopy showed mild bulb stricture with a large inflammatory ulcer with a sclerosus bottom.

In January 2009, oral corticosteroid treatment was introduced with a dose of $60 \mathrm{mg} /$ day. The abdominal pain partially improved, but promptly reappeared with identical macroscopic lesions at upper endoscopy. Azathioprine $125 \mathrm{mg} /$ day and infliximab $5 \mathrm{mg} / \mathrm{kg}$ (300 mg) scheduled at weeks 0, 2, 6 and every 8 weeks were then introduced. After 8 infliximab infusions, the gastric pain did not disappear, with a significant social impact on the patient's life (work absenteeism a week per month). We decided to optimize the treatment by increasing the azathioprine dose to $150 \mathrm{mg} /$ day and infliximab to $10 \mathrm{mg} / \mathrm{kg}$ (600 mg) every 8 weeks. The patient received three new injections of infliximab, but without 
Guellouz et al.: Cephalic Duodenopancreatectomy for Hyperalgic Duodenal Crohn's Disease Fistulized in the Pancreatic Gland

clinical improvement. Surgery was considered at that point, but gastrojejunostomy was excluded because of evidence of proximal jejunal wall thickening on magnetic resonance enterography. We then switched to another combo therapy with subcutaneous methotrexate injection $25 \mathrm{mg} /$ week and adalimumab $160 \mathrm{mg}$ followed by $80 \mathrm{mg}$ at 2 weeks and by $40 \mathrm{mg}$ every other week. No improvement was noticed after 3 months of this new treatment strategy. The isolated gastric pain became stronger, leading to complete socio-professional inability and requiring daily use of opioid medications. The failure of two lines of combined treatment led us to a salvage surgical option.

A median laparotomy was performed. Abdominal exploration showed two short inflammatory small bowel stenoses 50 and $70 \mathrm{~cm}$ from the angle of Treitz. The stomach was plate with a retracted aspect of the bulb. The bulboduodenal block was inflammatory and thickened. Cephalic duodenopancreatectomy and cholecystectomy were performed. The pancreas was hard at section. The jejunal stenoses were left in place in the absence of tight stricture. Histological analysis reported a large fissuring pylorus ulceration with micro abscesses reaching the pancreas (fig. 2).

Regarding the severity of the disease, adalimumab $40 \mathrm{mg}$ every other week was maintained after surgery to prevent CD recurrence. Six months after the surgery, the patient had stopped antalgic treatment and did not have residual abdominal pain. He had gained $11 \mathrm{~kg}$ weight and had no diarrhea with pancreatic enzymes.

\section{Discussion}

We report the unusual case of a patient with a hyperalgic giant ulcer of the bulb revealing CD complicated despite heavy medical therapy by fistulization in the pancreatic gland leading to surgery. To our knowledge, this is the first reported case of cephalic duodenopancreatectomy performed for upper digestive CD.

The prevalence of upper GI tract involvement in adult CD has been shown to be very low $(0.3-5 \%)$ [2]. Occurrence of epithelioid granulomas is still considered the histological hallmark of gastric $C D$, but performance of biopsies remains poor [3, 4]. The high frequency of H. pylori-negative gastritis in $\mathrm{CD}$ has been reported years ago [5]. Histological abnormalities with focal acute inflammation mainly in the duodenum and the gastric antrum in asymptomatic CD patients with normal upper endoscopy were confirmed in several retrospective studies [3]. In a case series of 49 patients with CD, more than $75 \%$ of the patients had abnormal gastroduodenal biopsies, but only $9 \%$ had granulomas [3]. More recently, a prospective study in 119 consecutive patients who underwent systematic upper endoscopy reported that macroscopic lesions were found in $16 \%$ of the cases, but only $7 \%$ of the population were symptomatic [6]. Here, we describe a patient having predominant and severe duodenal CD with gastric granulomas. Different endoscopic aspects of gastroduodenal CD have been described: granular mucosa with patchy erythema, multiple focal erythematous spots, friability and nodular thickening are frequently described, but varying degrees of superficial or deep ulceration also may be seen [7]. Stenosis is the major complication in the upper GI tract in CD, and duodenal fistulae are seldom detected during surgery. Most of the fistulae are cologastric or ileogastric [4]. In our observation, the patient presented unusual duodenal CD with a plugged perforation in the pancreatic gland.

Medical treatments have been shown to be effective in upper GI CD patients [3, 5]. Excellent responses to steroid therapy are well known in the gastroduodenal presentation of CD [3]. Immunosuppressive therapies have been used in some cases, but there are insufficient data on the efficacy of these treatments in upper GI CD [8]. Regarding anti-TNF therapy, 
Guellouz et al.: Cephalic Duodenopancreatectomy for Hyperalgic Duodenal Crohn's Disease Fistulized in the Pancreatic Gland

Annunziata et al. [6] recently reported clinical response and mucosal healing in more than $70 \%$ of upper GI CD patients treated with infliximab. However, all their patients had a mild and non-complicated form of gastroduodenal CD. Surgery of upper GI CD is only considered in exceptional cases when medical treatments are ineffective, and gastrojejunostomy is the most common procedure for gastroduodenal refractory CD lesions [3]. Here, we report the first case of an upper GI and fistulizing CD patient with a failure of steroids and two different anti-TNF therapies (infliximab and adalimumab) requiring cephalic duodenopancreatectomy for severe and refractory abdominal pain.

\section{References}

1 Pariente B, Cosnes J, Danese S, Sandborn WJ, Lewin M, Fletcher JG, Chowers Y, D’Haens G, Feagan BG, Hibi T, Hommes DW, Irvine EJ, Kamm MA, Loftus EV Jr, Louis E, Michetti P, Munkholm P, Oresland T, Panés J, Peyrin-Biroulet L, Reinisch W, Sands BE, Schoelmerich J, Schreiber S, Tilg H, Travis S, van Assche G, Vecchi M, Mary JY, Colombel JF, Lémann M: Development of the Crohn's disease digestive damage score, the Lémann score. Inflamm Bowel Dis 2011;17:1415-1422.

-2 Tan WC, Allan RN: Diffuse jejunoileitis of Crohn's disease. Gut 1993;34:1374-1378.

-3 van Hogezand RA, Witte AM, Veenendaal RA, Wagtmans MJ, Lamers CB: Proximal Crohn's disease: review of the clinicopathologic features and therapy. Inflamm Bowel Dis 2001;7:328-337.

-4 Grübel P, Choi Y, Schneider D, Knox TA, Cave DR: Severe isolated Crohn's-like disease of the gastroduodenal tract. Dig Dis Sci 2003;48:1360-1365.

-5 Halme L, Kärkkäinen P, Rautelin H, Kosunen TU, Sipponen P: High frequency of helicobacter negative gastritis in patients with Crohn's disease. Gut 1996;38:379-383.

-6 Annunziata ML, Caviglia R, Papparella LG, Cicala M: Upper gastrointestinal involvement of Crohn's disease: a prospective study on the role of upper endoscopy in the diagnostic work-up. Dig Dis Sci 2012;57:16181623.

-7 Tanaka M, Kimura K, Sakai H, Yoshida Y, Saito K: Long-term follow-up for minute gastroduodenal lesions in Crohn's disease. Gastrointest Endosc 1986;32:206-209.

-8 Mottet C, Vader JP, Felley C, Froehlich F, Gonvers JJ, Juillerat P, Stockbrügger R, Angelucci E, Seibold F, Michetti P, Pittet V; EPACT II Study Group: Appropriate management of special situations in Crohn's disease (upper gastro-intestinal; extra-intestinal manifestations; drug safety during pregnancy and breastfeeding): Results of a multidisciplinary international expert panel-EPACT II. J Crohns Colitis 2009;3:257-263.

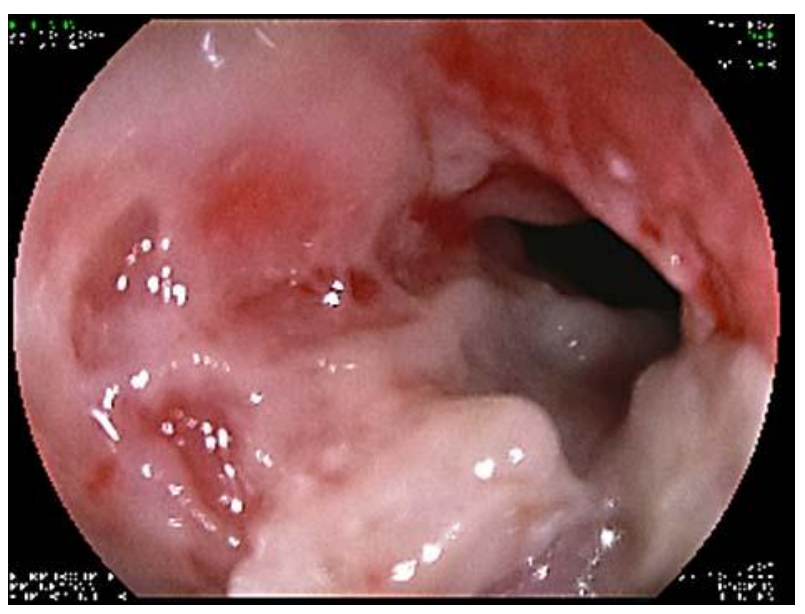

Fig. 1. Upper digestive endoscopy in a 33-year-old man with abdominal pain, anorexia and weight loss. The images demonstrated heterogeneous lesions, with a giant and deep ulcer of the bulb with a mild stenosis. 
Guellouz et al:: Cephalic Duodenopancreatectomy for Hyperalgic Duodenal Crohn's Disease Fistulized in the Pancreatic Gland

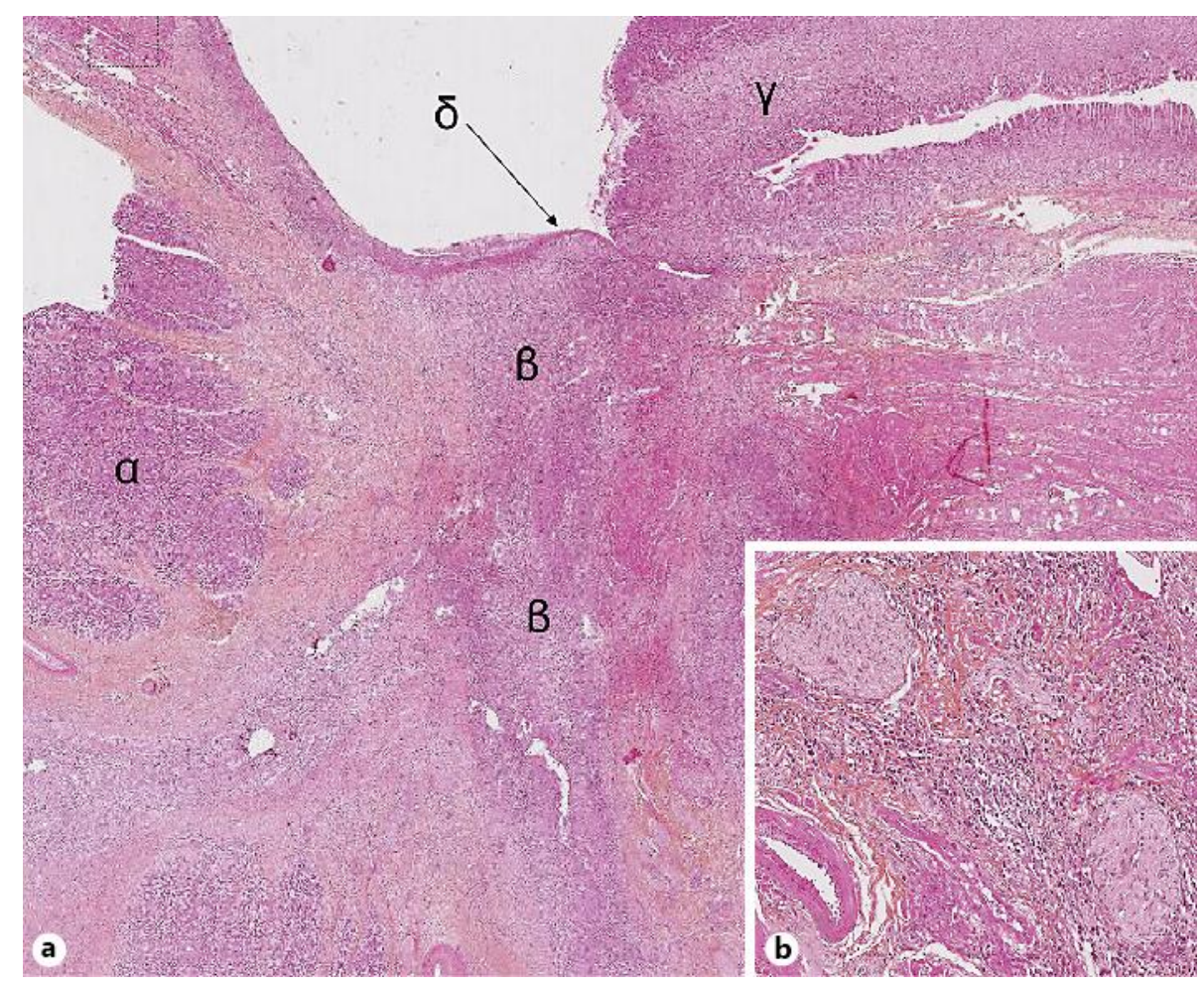

Fig. 2. Deep gastric fissuring ulceration with extension of the inflammatory process at the pancreatic gland (hematoxylin-eosin stain; original magnification: $\mathbf{a} \times 2, \mathbf{b} \times 40$ ). a Pancreatic glands $(\alpha)$, deep fissuring ulceration $(\beta)$, abrupt gastric mucosa ulceration $(\delta)$, normal gastric mucosa $(\gamma)$. $\mathbf{b}$ High magnification of the stamp on the top left corner; polymorphic inflammatory infiltrate in contact with hyperplastic pancreatic nerve fibers. 